\title{
14 \\ LABOR CONVENTIONS, ECONOMIC FLUCTUATIONS, AND FLEXIBILITY
}

\author{
Robert Salais
}

\section{FLEXIBILITY AND CONVENTIONS: THE PROBLEM}

The term "flexibility" is nowadays used to refer to an ensemble of properties which must be possessed as much by the forms of economic regulation as by the enterprises themselves. These properties correspond to several types of empirical phenomena: the development of uncertain markets where a variable demand manifests itself in an unpredictable manner over time; the growing differentiation of products following a closer analysis of the needs of demanders; the tendency toward quality competition (and no longer only price or cost competition); the growing dynamism of small organizations confronted by the bureaucratic rigidity of large ones; and the call for the polyvalence, autonomy, and initiative of workers in production associated with the deployment of flexible, computer-assisted technologies, etc. In sum, while economic thought, orthodox or heterodox, is largely based on the predictability and homogeneity of behavior, flexibility confronts us with an economic universe which increasingly takes on, for its participants, a character of heterogeneity and uncertainty.

The aim of this chapter is to sketch out research into labor flexibility from the perspective of the "economics of conventions" (économie des conventions), an approach elaborated in a series of articles recently presented in a special edition of La Revue Economique (1989). Three major questions raised by the flexibility of labor will be examined in the attempt to utilize the economics of conventions. But first I shall review briefly the basics of the approach that will be used in the discussion that will follow.

\section{The nature of the compromise underpinning the labor relations between employers and wage-earners}

For several decades, the relative security of employment in big enterprises, the existence of social rights and unemployment insurance guaranteed by the state, together with the standardization and routinization of work, diverted attention from the uncertainty intrinsic to labor relations. This uncertainty arises out of the conflicting interests of employers and wage-earners, and carries over into established agreements and commitments with respect to work quality and effort. The need for flexibility, which arose out of the crisis of the 1970s, called into question these earlier social agreements and made them appear for what they were: on the one hand, regulations and, on the other, particular regulations belonging to a certain regulatory regime. In other words, such conventions permitted only one efficient mode of regulation among many pathways 
which could have, in principle, been taken as a response to uncertainty. This led to the necessity to ask oneself which social form assures the resolution of uncertainties specific to labor relations (Salais and Thévenot 1986). The need for flexibility provokes a series of questions: can labor relations function without a certain overall set of legitimating principles in spite of the fact that flexibility makes impossible a uniform model of contract? Under these circumstances, what is the origin of its taken-for-granted character? Does the unilateral authority of the employer provide sufficient basis for this legitimacy and one which assures the respect for commitments? How is one to conceptualize both agreement and conflict within the same system of regulation of labor? What is the relationship between rules of work and norms of productivity?

\section{The necessary link between the analysis of labor and that of the product}

Labor flexibility calls into question the relations between the management of labor, the product, and its market, in the mass production system. If, for example, sales revenue becomes unpredictable, the wage cannot be fixed in the short term and must depend, in one way or another, on what happens on the market for the product. Long production runs for the same homogeneous product limits labor to certain repetitive and standardized tasks, to a narrowly defined quality of work. Adapting oneself to the variety of quality of demand on a fluctuating market necessitates a redefinition of work qualities. It is clear also that the connection between the quality of work and the quality of the product established by flexible methods is not limited to the enterprise. Rather it brings into play the formation and reproduction of the qualities of the work force in society as a whole. If wage-labor is characterized by the divorce between work and the product of work, then it rests, at the same time, upon their articulation. In what way is this articulation modified by flexibility?

\section{The complexity of rules at work and the variety of forms of flexibility}

Flexibility calls upon us to think about diversity and complexity. In so far as the variability, differentiation, and heterogeneity of product qualities become the determinant components of competition, our hypothesis, inspired by earlier research into conventions ${ }^{1}$ (Thévenot 1989; Eymard-Duvernay 1989a) is that it is no longer possible to reduce all forms of firm organization, work rules, and wage determination to a single model. Rather, we can hypothesize that several models of labor conventions exist and that each one presents a specific form of flexibility at work and is adapted to a particular economic universe. Our ambition is to go beyond the vision of flexibility as an empirical critique of the dominant model of production (a critique which we shall return to at the end of this chapter) toward a more positive and diversified conception. We shall propose a plurality of labor conventions founded upon the qualities of the products of work. 


\section{WHAT IS A CONVENTION? ITS APPLICATION TO LABOR ${ }^{2}$}

\section{Convention, contract, and norm: points of reference}

The word "convention" signifies a taken-for-granted rule commanding spontaneous obedience, the result of a founding agreement (the Geneva Convention, for example) and the founding moment (the Convention Constituante). The choice of this term is aimed at underlining the fact that agreement between individuals, even when limited to a shortterm contractual transaction, is not possible without a shared framework, an external point of reference going beyond the simple encounter between separate wills. The economics of conventions, then, rejects the neoclassical postulate according to which the agreement of the parties - the labor contract - can only take place via prior written specification of every detail; reflecting identical, optimizing rationalities and intentions. Nonetheless, we reject the opposing sociological postulate according to which agreement results from a submission of individuals to exogeneous norms which either impose themselves from the exterior (being decreed, for example, by social institutions or by labor law, etc.) or are completely internalized in the consciousness of actors without their awareness. (See the extract "Durkheim and the contract", below, in which we suggest that Durkheim develops a more subtle view of contract than usually understood.)

In other words, this middle-ground solution consists in the notion that the convention is a system of reciprocal expectations regarding the competence and behavior of individuals, conceived and accepted as taken-for-granted (Favereau 1986). For efficient coordination to take place, there is no need for these expectations to be written or objectified in any way. Indeed, it would make little difference since their degree of generality or efficacy would not be affected by being written down, for the degree and the modalities of exteriorization of the rules vis-à-vis individuals depends on the system of conventions in force.

\section{Durkheim and the contract}

The concept of convention has a larger theoretical relevance than contract or norm in analysis of labour flexibility. It seems to us close to the methodological rules which were outlined by Durkheim in his "The Division of Labour in Society," 1893. Criticizing Spencer and liberal economists, he questioned the contractual relations within the division of labor (see, also, Didry 1991):

Contractual relations necessarily develop with the division of labor because the latter is not possible without exchange, of which the contract is the juridical form. Doubtless it is an error to believe that all social relations can be reduced to the contract: all the more so given that the contract presupposes something other than itself; nevertheless there are special connections which have their origins in the wills of individuals. There is a consensus of a certain type which is expressed in contracts and which, in its higher forms, represents an important 
factor in the general consensus [Durkheim's emphasis]....

But for the general result to be obtained, it is not sufficient that the public authority ensures that commitments are respected. Rather, it is necessary - at least in most cases - that commitments be spontaneously respected. If contracts were only observed because of force or the threat of force, contractual solidarity would be singularly precarious.... On. the other hand, consider the hypothesis that, in order to eliminate this danger, the free consent of individuals suffices. This is true but the difficulty is not so easily conjured away. For, what can be said to constitute "free consent"? Verbal or written acquiescence is not sufficient proof; forced acquiescence is not impossible. All constraint must therefore be absent. But what is the origin of constraint? It does not consist in the direct employment of violence because even indirect violence eliminates liberty....

In a given society, every object of exchange at every moment has a. definite value which one can call its social value. One can perceive quite easily the principal conditions according to which social value varies. These are, above all, the sum of efforts necessary for the production of the object, the intensity of the needs it satisfies and. finally, the breadth of the satisfaction it brings....

This definition given, we can assent that the contract is only fully consented to if the services exchanged have an equivalent social value. Under these conditions, eveyone receives the thing he desires and delivers that which he gives in return for what both one and the other are worth. This equilibrium of wills, recognised and consecrated in the contract, produces and maintains itself automatically since it is simply a. consequence and alternative form of the very equilibrium of things. It is truly spontaneous.

(Durkheim 1967:375-7)

Durkheim emphasizes that the contract itself, as the basis of the contractual relationship, cannot be limited to the simple meeting of two free wills. Respect for commitments demands the necessary mediation of a third party who guarantees it and supplies a legal recourse in the case of observed violations. Durkheim calls this intervention by the regulations of a public authority, the "law of contracts." But this is not sufficient: the contractual relationship must be respected beyond free consent. The equilibrium of wills must be "spontaneous" and this is only possible because the "equilibrium of wills" is simply a consequence and another form of the "equilibrium of things." This is due to the fact that the equivalence of social values is inscribed in things. And this equilibrium must be held beyond constraint whether it be the effect of authority or of a particular form of violence. Otherwise the relationship would appear to be of a "singular precarity," hardly borne out by observation.

It appears that, thus conceived, a contract between two individual wills could be considered as part of a convention which, at the same time, goes beyond it, 
legitimates it and regulates it in its detailed aspects. Within this condition, the contract is clearly more than an exterior norm, for the convention which founds the contract simultaneously rests on rules (the law of contracts), on a principle of equivalence of exchanged objects, common to contractors and on a spontaneous agreement (agreement beyond consent and constraint). In fact, the contractual solidarity described by Durkheim presents a number of the traits which we shall call, later in this chapter, the market labor conventions. One will note that the equivalence of social values exchanged are considered not only in terms of quantity, but also, fundamentally, in terms of the equivalence of qualities (as it is expressed in the systematic use of terms such as "the sum of efforts," "the intensity of needs," and "the breadth of satisfactions"). At the same time, Durkheim limits its scope of validity to relations where "the values exchanged are really equivalent" (415); opening up, for Durkheim, the possibility of other modalities of solidarity such as "organic solidarity." For us, this means that we must conceptualize several types of conventions.

Two points, however, should be made concerning the current analysis of labor relations. First, conventions do not exclude logical contradiction. On the contrary, they are a form which enables the coordination of contradictory interests based on opposed logics, but which need to be brought together to be satisfied. Clearly, if the entrepreneur is interested by the product of work and the workers by the wage, only their meeting and their activity in the enterprise are capable of satisfying these two interests. The situation is indissolubly conflictual and cooperative.

Second, the convention, as an empirical phenomenon, does not exclude conflict. For a given regime, it is the framework within which the conflicts are conceptualized and resolved, for it formulates the pertinent variables around which conflicts arise and are resolved. For example, conflict over the size and periodicity of hourly wage increases is an everyday occurrence. Nobody, however, questions the idea that the hourly wage rate is central to the conflict. Yet there exist other forms of remuneration such as piecework or monthly salaries (not based on hours of work), wages linked to the performance of the enterprise, etc. which imply other systems of production, alternative organizations of work, and even other forms of consumption. But the conflict takes place within a convention to which all the participants conform without thinking; a convention according to which the pertinent variable and the fair evaluation of work is the hourly wage rate. The existence of a prior convention only becomes apparent to the participants in moments of crisis when the form of earnings itself is contested rather than the level or rate of increase.

\section{Labor conventions and equivalence}

As in most economics, we assume that "equivalence" is the foundation of all exchange, i.e. exchanged objects have the same value for all the parties to the transaction. For this situation to be transformed into the basis of a stable and positive coordination between economic agents, equivalence must rest upon a common principle; a scale and method of evaluation common to all the parties involved. This is an important and necessary 
assumption. In fact, one cannot conceive of economic coordination founded upon the prior and permanent negotiation of rules between agents, which would imply suspicion and lack of trust. Coordination is either spontaneous or nonexistent.

The application of the concept of convention to labor relations is therefore very complex. The objects that establish the equivalence for individuals in this relation are problematic as are the principles according to which the objects are evaluated.

Figure 14.1 presents the three points which must be brought together by a theory of conventions applied to labor:

1 Labor has no material existence independent of and separate from the person of the worker. It cannot be an object over whicha commodity transaction can be made (cf. Marx 1867: V. 2). Only the product of work

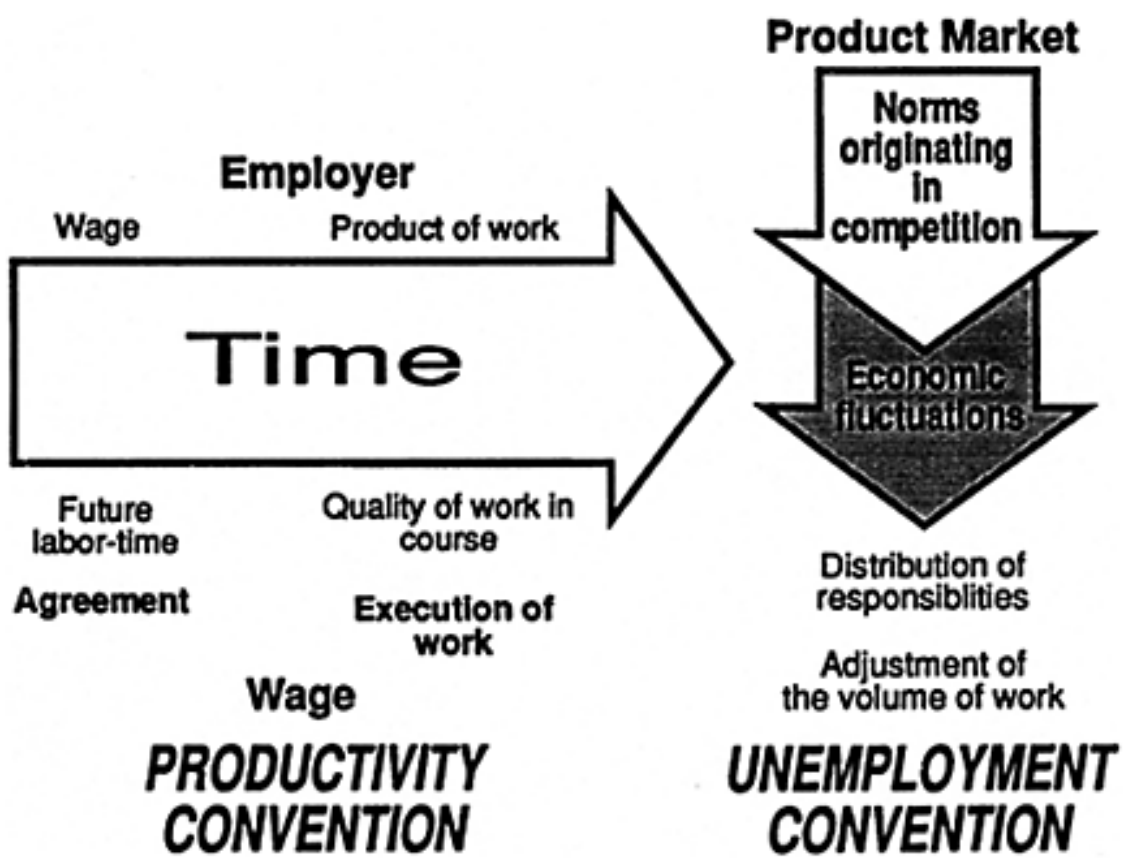

Figure 14.1 The domains of action of unemployment and productivity conventions

can be the support for such a commodity exchange but, except for certain "extreme" labor conventions where the wage relation is disappearing, the product cannot be the pivot of an agreement, because the product is not yet in existence when the agreement has to be concluded. It must be replaced by something else.

2 The labor relation must be concluded between the entrepreneur and the wage-worker prior to the realization of work and the sale of the product. It consists of two successive operations: agreement (hiring) and work or production. Separated in time, these two operations nevertheless cannot fail to be in relation, which influences in 
return their content.

3 The labor relation unfolds in the overall framework of the market: the value of the product of work anticipated by the entrepreneur is either validated or not by price on the product-market. This difference between the forecast and the result must be capable of being absorbed without disrupting the practice of the current labor relation.

These three points correspond to three moments which are linked in time and which must be theoretically presented as such:

a) hiring

b) work in production; and

c) the realization of the product on the market.

The unity of these moments is realized by the economic cycle of the product of work, considered from the point of view of the labor relationship. The convention of productivity covers the first two moments and the convention of unemployment, the last one.

\section{The convention of productivity}

The convention of productivity refers to something not yet in existence, future labor-time. The convention of productivity thus establishes a compromise between two equivalences:

1 During recruitment, the wage is exchanged against future labor-time; this is the first wage/labor-time equivalence in labor relations. Constituted around an immediate transaction, this first equivalence takes on a market form. It is defined around a rule or standard for setting wages.

2 Thereafter the wage-earner puts to work his labor-power in production, transforming labor-time into a product; this is the second labor-time/ product of work equivalence. Unfolding in and referring to labor-time, this second equivalence does not, in essence, take on a market form. It can be constituted by various principles of equivalence (to be defined theoretically in the last part of the chapter) which also define the work rules.

A definite social relationship between wage and productivity (defined both in terms of quality and effort) results from this compromise. This compromise is ambivalent because it mixes two equivalences which are different in nature and provokes the uncertainty with respect to productivity. It is thus prominent in the contemporary search for flexibility. At the conclusion of the labor relation, which takes place around a wage/future labor-time exchange according to a definite wage rule, nothing guarantees that the second labortime/product equivalence will be realized in accordance with the expectations of the entrepreneur.

\section{The unemployment convention}

Economic fluctuations in the product market (with respect to quantity, price, or quality) render necessary the existence of stable rules of short-term adjustment on the quantity (and quality) of work engaged via the convention of productivity. The unemployment 
convention defines these rules of work adjustment, and the respective roles of workers and employers in it.

The assumption can be made that workers' and employers' responsibilities in this adjustment depend on the structure and distribution of property rights. For instance, in industrial labor conventions (see pages 296-8) the entrepreneur owns the resources in capital and organizes the production process under his responsibility; as a consequence, he disposes of the monetary amount of sales. It has thus the right to adjust, under his own responsibility, the number of employees salaried by his firm; but as a counterpart, fired workers can benefit from social indemnities.

Since the convention of productivity equilibrates two conceptions of the fair relationship existing between work and remuneration, short-term adjustment must endanger neither the rule governing the wage, nor the rules governing work effort and quality. It is endogeneous to both sets of rules. For example, in labor conventions founded on rules derived from Taylorism, the short-term wage rate is inflexible, and adjustment to economic fluctuations takes place around the number of work stations occupied. Here adjustment takes an impersonal form such as the "last in, first out" rule or criteria relating to the age of early retirement in the case of overmanning.

\section{Conventions, wage-determination, and work rules}

The continuity of the labor relation is threatened by economic fluctuations; demand fluctuations can erode expected profits; the same problem can arise from internal fluctuations of the quality of work and the effort of the workers. Conventions thus must rest upon an "understanding" of fluctuations which creates shared (or "common") knowledge by which participants cope with fluctuations. Both the knowledge of these fluctuations and the coping mechanisms must be invested with a legitimacy such that, if the threat posed by fluctuation is ongoing, disagreement leading to rupture of the convention is rare and usually contained within narrow limits. It is necessary then that they draw simultaneously on both principles of equivalence, in constructing a general set of expectations about legitimate wage and work rules.

Wage and work rules therefore must fulfill two requirements: first, they must mobilize knowledge about the uncertainty of the labor relation and then, they must manage this uncertainty in a legitimate way. They are not, therefore, merely rules of action or of judgment. They are also cognitive rules which provide information and allow participants to define and evaluate (Favereau 1989). They consist of shared values, classifications, variables, criteria, and ratios and serve as instruments for measuring or judging the ongoing functioning of conventions.

Take, for example, the use of the rules based on Taylorism. Organization into discrete tasks renders work measurable and predictable. Jobs in the workplace are based on a classification of concrete tasks - elementary operations - which define the quality of work. A sort of codification associates a variable, abstract amount of time, with each operation in the classification. A job can thus be defined as a sum of elementary operations and an amount of time prescribed for effort. An output norm (effort) is then defined, together with an objective calculation of the wage rate around which wage bargaining takes place (labor-time/wage equivalence). Individual tasks can then be added 
together to permit the calculation of costs accounting of the firm. The productivity of labor is observable: labor-time can be assigned to the product (labor time/product equivalence) and effort measured. The firm can measure its profit and derive a norm by calculating its difference with the overall sales figure. Thus able to identify appropriate and needed labor-time in the form of concrete jobs in the workplace, the enterprise is able to convert any excess work time in the short term into overmanning or unemployment (convention of unemployment).

\section{MODELS OF LABOR CONVENTIONS}

\section{From the product of work and its quality toward work}

Labor conventions have their sources in the separation between work and its product; ${ }^{3}$ their domain is to define relations and connections between these two areas: work and product. If the evaluation of individual effort rested upon the simple exchange of products, the domain of labor would have no specificity; the analysis of the conventions defining the various forms of equivalence of products would suffice and we would need only study the quality of goods (Eymard-Duvernay 1989a and 1989b). ${ }^{4}$ Furthermore, in those cases where work is confused with its product, labor conventions and conventions of the quality of goods would be identical (consider, for instance, an economy solely composed of individual independent producers, without firms and wage-earners).

The approach adopted here begins with the product and advances toward work. It examines the quality of the product and the quality of work and analyzes how labor conventions affect their articulation. The first equivalence of the convention of productivity (labor-time/product equivalence) rests on product quality as it is defined by the organization of the production process and its technology. The rules of work and work activity are, therefore, closely associated with the rules defining the quality of the product and which are imbricated in the organization of production. Our task, here, is to specify the rules which define the quality of work in light of product quality, within the organization of production.

The second equivalence of the convention of productivity is that of the market. The wage rule belongs to this second equivalence. It must be defined in relation to the product and to the standard of quality established on the product market. This proposition is unusual in that it subordinates the role of the labor market in the determination of the wage to the product market. Wage rule determination, in other words, has its theoretical roots in the product market. For a given wage-rule, it is only the wage level and its variations which are determined by the labor market. This is clear in the extreme case where the remuneration of the individual comes directly from the sale price of the product; in this case, the form of the wage is the market price of the product. But the current price will depend not only on demand, but also on the number of individuals offering the same product and the same product-quality on the market.

We are left therefore with two axes to our model of product and labor markets. The first axis concerns work activity and the labor-time/product equivalence. At one end is the specialization of individuals and at the other the standardization of jobs. The second 
axis concerns the product market and the wage/labour-time equivalence. At one end may be found wage variability and at the other wage short-term fixity; each pole corresponds to a type of market: uncertain or predictable. These two axes define four pure models of labor conventions. These models will be elaborated in the last section of the chapter, but we shall first discuss in greater detail the choice of these two axes.

\section{The first axis}

Work rules determination (labor-time/product equivalence) counterposes the quality of persons to the qualification of jobs. This corresponds to the specialized/standardized product distinction. Making the quality of persons an alternative to the qualification of jobs leads to several oppositions (see, also, the "Idiosyncracy" extract). For the former, the organization of production is based on the specialization of persons and, for the latter on the standardization of tasks (and, beyond that, of work-stations). The quality of work, when it is specialized, is linked to individuals who have a quality based on knowledge and know-how (the mastery of a "trade") which only they possess. Standardization by objectifying the labor-process allows their personal qualities to be built into material and bureaucratic organization of the labor process. The skills needed to carry out tasks are standardized, with individuals no longer possessing specific qualities. We shall see later that, in these cases, the wage can therefore be attached to the job-description and not to the person. The organization of production which, in the former case, is based on a collective of workers, each with their own particular identity, rests, on the latter case when it is standardized, upon the connecting together of identified tasks and workstations across a particular deployment of equipments. In the first case (specialization), persons represent a valuable, capitalizable resource. In the second (standardization), tasks are costs to be reduced. Standardization, is, in effect, intimately linked to economies of scale as the only way to reduce average unit costs. Skill specificity, on the other hand, is linked to investment in the development of know-how and in the quality of labor. Expressed in the terms of industrial economics, specialization privileges economies of variety, based not on the length of the series, but on the range of products and the mastery of a variety of qualities.

\section{Idiosyncracy and economic analysis}

When economists want to study the variety of qualities of labor, they take as their point of departure, the levels of skill (as revealed by the classifications of work-stations in the wage-hierarchy). They consider, therefore, that work is already constituted as a factor of production which can be described objectively and standardized in terms of a classification of quality and of a measure of quantity - in terms of hours of work or number of jobs.

Nevertheless, the recognition of an opposition between quality of persons and qualification of jobs traverses economic analysis in diverse forms. A positive form based on the observation of large, rationalized enterprises, insists on the persistence of the idiosyncratic character of the labor process (Doeringer and Piore 1971) or on the role of effort-conventions which move the X-efficiency away from the production frontier (Liebenstein 1966) or, finally, on the strategic character of individual knowledge in the 
Hayekian tradition, 1945. A critical form uses the point of view of economic rationality - the neoclassical production function or the model of Taylor-to denounce those elements which prevent the attainment of an optimum and which result directly from the inopportune intervention of persons: the non-observability 5 of performance, opportunist behavior, corporatist alliances leading to monopolies on the labor market and restrictive practices, etc. Remember, for instance, the fundamental analysis of internal labor markets in large enterprises undertaken by Doeringer and Piore:

\begin{abstract}
Almost every job involves some specific skills. Even the simplest custodial tasks are facilitated by familiarity with the physical environment specific to the workplace in which they are performed. The apparently routine operation of standard machines can be importantly aided by familiarity with the particular piece of operating equipment.... In some cases workers are able to anticipate trouble and diagnose its source by subtle changes in the sound or smell of the equipment. Moreover, performance in some production or managerial jobs involves a team element, and a critical skill is the ability to operate effectively with the given members of the team. This ability is dependent upon the interaction skills of the personalities of the members, and the individual's work "skills" are specific in the sense that skills necessary to work on one team are never quite the same as those required in another.
\end{abstract}

(Doeringer and Piore 1971:15-16)

While Doeringer and Piore presumably refer to an alternative model of production where this idiosyncracy positively deploys its economic advantages (this being suggesting by their future work $^{6}$ ), their followers on this point (Williamson, Wachter and Harris 1975) tend to reduce the influence of such idiosyncratic knowledge to the "local conditions and particular circumstances" conceptualised by F.Hayek (quoted by Williamson et al.).

These specialized goods embody the quality of workers who make them and such products compete in markets based on quality and not (or not as much) on price or cost. On the contrary, a standardized good is produced by a known and widely available technology which gives no competitive edge to quality. For such a product competition is based on price. In the first case, information about the quality of the product is directly attached to recognition of the quality of the individual producers' work. In the second case, standardization permits such limits, which are both geographical and social, to be transcended as the standard spreads.

\title{
The second axis
}

Wage rule determination according to the product market opposes the wage variability to the short-term rigidity of wage. It opposes uncertain and predictable markets and separates dedicated and generic products.

The problem of the frequently observed divergence of empirical data from the neoclassical theory of labor market, empirically arises from the possibility that workers will engage in autonomous bargaining over the volume of work and the wage which blocks the instantaneous adjustment mechanism of the market. The short-term rigidity of the wage-level and the level of employment are phenomena foreign to the neoclassical 
market. It is well known that neoclassical hypotheses treat "work" as any other commodity; it is not separated in theory from its product.

The problem is to give a status to the short-term rigidity of the wage agreed to by the producer, in the theoretical framework of labor conventions. It is not a question of the stability of rules themselves - stability being a characteristic of all conventions - but rather that of the opposition between rules of rigid wages and rules of variable wages (Reynaud, 1986a and 1986b). Following the line of reasoning advanced above (from the product of work towards work itself), we shall look not so much to labor-market imperfections as possible explanation of these rigidities (the standard approach), but rather to types of product and their markets. In this way, we hope to show that for some types of product and market short-term rigidity of the wage can be efficient for the producer and the latter is then obliged to admit that market fluctuations for his product generate no information pertinent to the quality of work invested in it. Otherwise, he would, for example, reduce wages when the price of the product falls and choose more selectively its work force and cut working hours. This condition is due to the fact that since market fluctuations give no information about the product, variable wage-rates have no adjustment role and wage-flexibility, therefore not disposing of any market legitimacy, cannot serve as the basis for a convention between workers and entrepreneurs. It becomes, then, efficient for the producer to postulate the short-term independence of output level for his product vis-à-vis market fluctuations, and wage rigidity is then the only logical and legitimate convention.

Two product and market configurations emerge in these conditions. The first is the opposition between dedicated and general-purpose products and the second opposes uncertain and predictable markets. The bringing together of these two oppositions with the wage rigidity/flexibility opposition sheds light on the nature of the independence of output levels for the product vis-à-vis a fluctuating market.

Consider first the opposite situation. When the quality of the product is such that it is aimed at a specific need (defining what we called, in Salais and Storper, 1989, a dedicated product) the wage cannot but reflect the quality of work, which in turn is gauged by the value accorded by the buyer; the wage thus reflects price and quantity sold. For, in such market, the link between the quality of work and the satisfaction of the buyer is known and established. For example, a fall in sale price signifies a reduction in quality of the product and of the work that goes into it. The variability of price of labor, in this case, reflects the range of qualities of the product according to the range of customers' demands.

Wage rigidity as a rule is economically possible only if the variation in the value of sales signifies for the producer not variations in the quality of work, but only variations in consumer tastes or demands. This is the case when two conditions are met:

1 the producer masters the definition of quality (for example, he succeeded in imposing his standard of quality for all the producers of the product on the market, what we could call an "industrial standard"); and

2 the product is aimed at a large, identical, and anonymous demand (defining what we called, in Salais and Storper (1989), a generic product).

In this case, if demand falls, it is because the design of the product is out of step with the 
changing tastes of consumers, and not because the quality of work per se is inadequate. In other words, the quality of work and the satisfaction of the consumer are two separate issues.

The second way to conceive the wage variability/inflexibility distinction stems from the nature of the product-market. A generic product is, par excellence, the basis of a predictable market. The large number of potential buyers for a generic product allows the producer to calculate his risk in serving the market (for instance, by the use of quantitative and statistical techniques, regression to the mean ensuring a fluctuation around a medium-term trend). This allows planning, i.e. inflexibility, in the volume of work and in the wage. On the other hand, a dedicated product, aimed at a particular demand, defines an inherently uncertain market - no evaluation of the risk associated with demand, around which the producer can plan its production strategy, can be undertaken. The producer cannot make commitments in an uncertain market, nor can he arm himself against fluctuations in the future by (say) expecting to switch from one individual demand to another, either immediately or later on. As a consequence the adjustment of labour costs must be very flexible.

\section{FOUR MODELS OF LABOR CONVENTIONS AND FLEXIBILITY}

Four "pure" configurations of labor conventions are outlined here, but it should be remembered that any real situation is likely to contain a mixture of conventions. Nonetheless, each model should call to mind familiar empirical situations. 


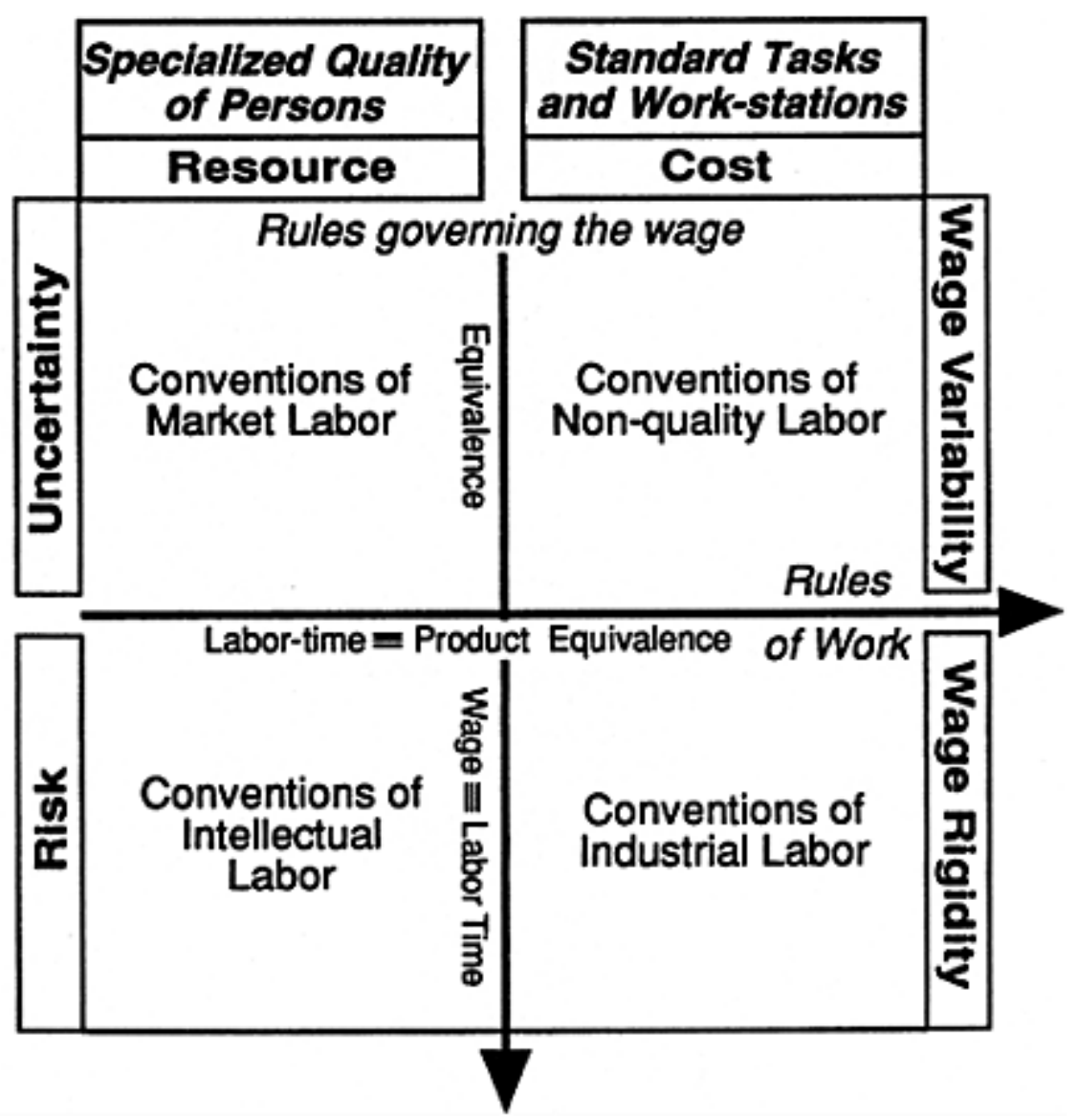

Figure 14.2 Four models of labor conventions 


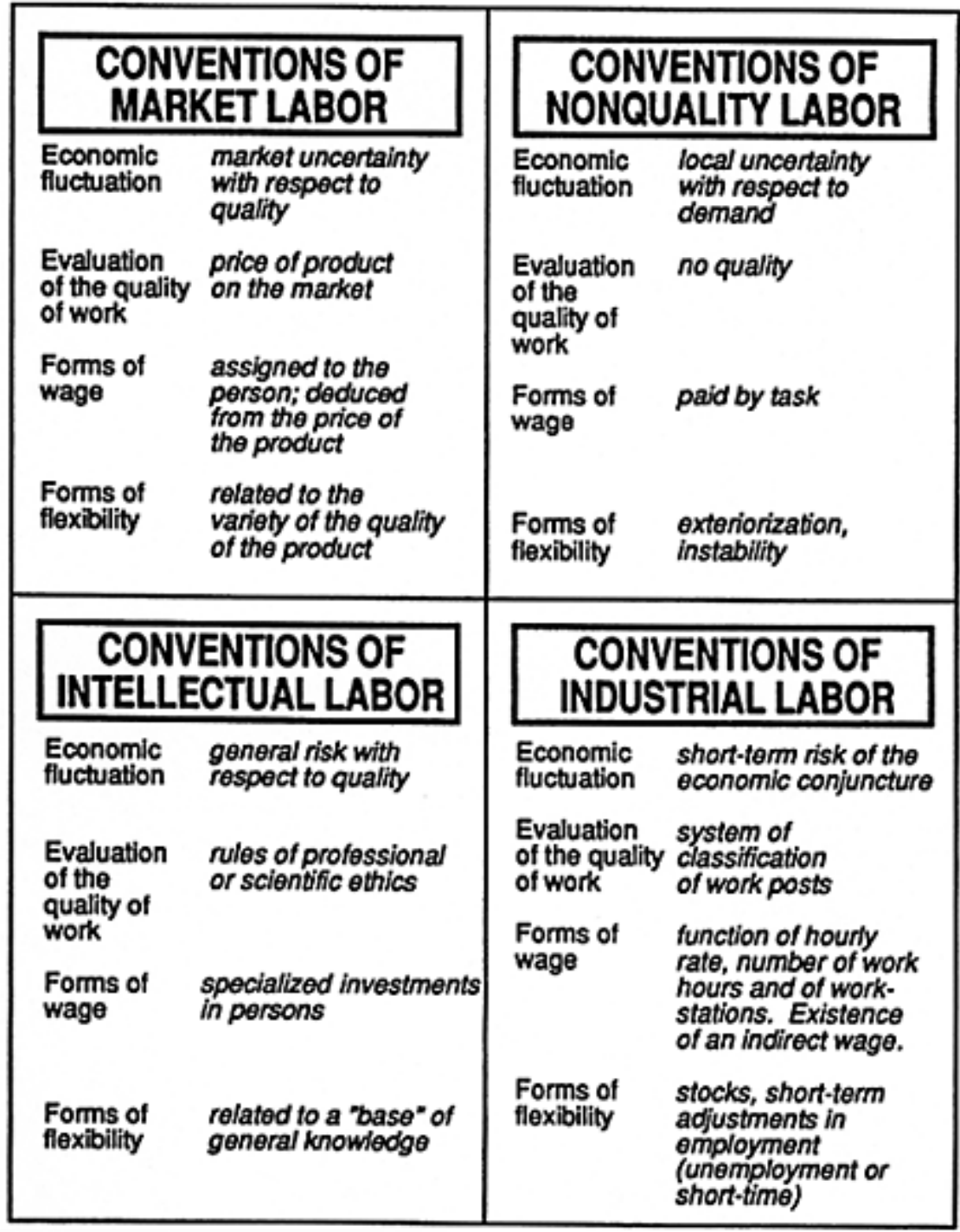

Figure 14.3 Economic fluctuations and flexibility of labor

The four models are summarized in Figure 14.2. We shall review each model in turn, describing their respective productivity and unemployment conventions, characterization of fluctuations, and type of flexibility. Each model is equipped with a form of labor flexibility ${ }^{7}$ adapted to a given economic environment, as shown in Figure 14.3. Note that "rigidity" is nothing more than a critique aimed at the particular flexibility of one model by the participants in another model. 


\section{Conventions of market labor}

Pictured in the top-left section of Figures 14.2 and 14.3 are those conventions where labor quality manifests itself directly in the product. ${ }^{8}$ The product is, both, specialized (workers master the know-how for fabrication) and dedicated (satisfaction of a unique taste). Quality is evaluated by the intensity of demand. The price obtained for the product evaluates the quality of work performed. The contribution of labor tends, in these conventions, to be conflated with the quality of the product and two principles of equivalence are reduced to a single one, that of the equivalence labor-product. The labor market is regulated by the wage, but the latter is in turn a reflection of the price of the product. The "union rate" negotiated by members of a "trade," the price of the product accomplished by a workteam and negotiated with him and the piece rate in certain activities are forms of payment which can be referred to as rules of conventions of market labor (Mottez 1966).

The convention of productivity here is often confused with the nature of the product market, with its numerous, specific, potentially unique qualities of demand. The regulation of the labor market takes place, therefore, not by unemployment (that is, by inactivity of qualities of work), but by geographical mobility from one local labor market to another or by retraining into another quality. In effect, individuals take with them the quality of the product (a quality which cannot be objectified independently of its creator). The convention of unemployment is, thus, a convention of worker mobility and learning of specialized skills.

The community of "the trade" is a historical example of conventions of market labor. In the French rolling mills before the installation of mechanical trains after World War II, the operator was "somebody" (Verry 1955). His authority and prestige were founded on the practical, technical knowledge needed for the manufacture of iron sheets. This enhanced the value of the "tricks of the trade". The training of rolling mill operators took place on the job and followed the hierarchical organization of the workteam. The wage of the group leader was often calculated in terms of its overall output whereas the other members of the team were paid a percentage of this basic remuneration. This scarce, skilled labor, shifting as it did from one mill to another, was snatched up by the Lorrain ironmasters (Noiriel 1984). It was hardly surprising then that the late-nineteenth-century promoters of harmony between capital and labor exalted the liberal values of setting up one's own business, since this resembled the professional ethics of "the trade" (the spirit of independence and autonomy). These values were, in turn, denounced by the advocates of industrial rationalization:

The worker is no longer that small businessman who, in the determination of the price by negotiation, undertakes - at the same time that he elaborates a definition of the fair price - an apprenticeship in the management of his future small business.

(Mottez 1966)

The relevant economic fluctuation here has to do with uncertainty over the product qualities that will be in demand. This uncertainty is "local" in the sense that the market is 
defined by a close acquaintance between producers and consumers, this alone permitting the circulation and elaboration of the information necessary for exchanges when specialized goods based on an inherited know-how and specific technologies are in demand. For the producers, the problem is not fluctuating in the volume of demand, but variation in the qualities which compose it.

Flexibility thus consists of having available workers whose range of skills and equipment, whose polyvalence enables them to deal with a variety of quality of products. The price of the product is the only possible standard of quality of work in these conventions, and such flexibility allows sufficient adjustment to price variations. The correct strategy for the producer is orientation toward qualities whose price is rising.

Market uncertainty over quality is mastered to the extent that the definition of qualities by the producer corresponds to that of consumers. In this case, even if certain clients abandon him, he can find others, especially if his product scope serves numerous industries and geographical markets. Thus potential failure in local markets can be dealt with by output shifts, external renewal of the workforce, internal training or by a reorientation towards other market territories where consumers tastes are still consistant with output.

\section{Conventions of intellectual labor}

Seen on the lower left section of Figures 14.2 and 14.3, these give priority in both the configuration of the product and the organization of the production process, to investment in specific skills. But, unlike in the preceding cases, where the product imbues work with particular qualities, here the quality of the individual's skills is what imbues the product with its qualities. This quality, moreover, consists in the creation of new knowledge, in the mastery of a unique know-how and in the creation of new markets for products based on innovations. The difference also arises from the fact that these are specialized products which eventually take a general and universal form. The specific knowledge which goes into fabrication of a product with recognized qualities, in effect, creates the market. In the final analysis, such innovation-based products are not subject to competition and thus do not have prices fixed by the market. The economic value of the product is essentially that of the knowledge-based work that goes into it; as a result, there is a single wage/work equivalence.

The productivity convention is based upon internal — scientific — rules governing the quality of work. Individuals, who are the objects of intangible investment, are a fixed resource. Producers are sheltered from the classic conjunctural conditions of the predictable market. The only possible market sanction they face is "structural"- the absence of any market opening for the commodity.

Unemployment is attenuated by the variable or flexible quality of the product of intellectual labor, in other words, by changing the product. When there is no market for the product, this signifies that the quality is not recognized by potential buyers and that the product must be changed by harnessing the knowledge which is specific to the work force in question. This change is possible in the sense that, unlike market labor conventions, these skills are not simply "tricks of the trade", but rather generalizable empirical methods, i.e. scientific methods. Here we encounter the differences identified 
by Piore (1972), which define the quality of workers according to two conventionsystems: higher and lower primary sectors distinguished, respectively, by the ability to adapt general rules to variable concrete situations and by routine familiarity with a given technology, product or firm. High-technology enterprises, whose priority is research and development, and other innovative or creative firms participate in these conventions. In effect, the producer must succeed in giving his creative work a universally acceptable form, unlike the work of the artisan.

Producers do face risk over the qualities of market demand, in which the real issue is whether investments in human capital are concordant with the evolution of demand. In effect, risk concerns the very existence of a market. Flexibility has to do with the quality or configuration of the product. Its broad scope is linked to the extent to which concepts and the methods can be universalized and to the possibilities for adaptation of existing products and industrialization of new products.

\section{Conventions of non-quality labor}

Seen at upper-right hand of Figures 14.2 and 14.3, these conventions are based on standardization of tasks and permit the utilization of interchangeable individuals, whose identity has no importance in the quality of work. In effect, standardization suppresses individual qualities. More precisely, worker identity is external to work itself (e.g. family membership or membership of a rural or ethnic community), having no place in the world of work. Personal qualities generated outside the workplace are nonetheless important in determining the appropriateness of an individual to a given job. Thus, the employment of individuals whose skills have, strictly speaking, no market-price permits them to be evaluated by low wages. Wages are low in part because they do not reflect cost of investment in reproduction of skills. This is a basic difference from the two preceding models of conventions, where quality of work directly reflects that of individuals and wages must cover reproduction of these qualities. Such a wage level is a precondition of the stability of those conventions. Here, by contrast, temporal stability comes from the durable existence of a labor surplus (considered in these conventions as a kind of free and natural resource).

A good example of such conventions is the replacement, thanks to standardization, of men by women in many jobs, as well as the massive employment of rural or immigrant labor. In both cases, the nonwork qualities of these groups (i.e. peasant ties or household roles) are more important than skills. Sabel (1982) distinguishes three categories of workers, who illustrate non-quality labor conventions: "peasant-workers," "would-be craftsmen," and "ghetto-workers." The universe of reference of these workers is external to the jobs that they occupy at any given moment. Peasant-workers accept unstable employment and can tolerate unemployment since they can either return to agriculture, earn supplementary income, or be aided by their community. Members of the same community can often assemble themselves in a single enterprise and continue to apply the hierarchical or even clan-based organization of their community under the codified appearance of the relations within an enterprise (Bernoux, Motte, and Saglio 1973). Lacking initial skills values in the market, would-be craftsmen are ready to accept anything in order to penetrate the world of the factory. The absence of any long-term 
project condemns ghetto-workers to dead-end jobs and to an acceptance of the moral judgment which upholds their incapacity to undertake anything better.

Such conventions typify situations where employment is unstable or precarious. They can also be encountered when products of standardized labor are dedicated to one or more particular demands. A classical illustration of this in industrial economics is the case of subcontractors lacking knowledge specific enough to give them independence on the market. One can also associate these conventions with the "sweating-system," where work (at home or in small family enterprises) has lost the independence of "the trade" without gaining autonomy by access to the market. Production is placed under the direction of the market (price, volume or quantity) by the middleman who places the order. In this way the sweating system plunges workers into uncertainty.

Wage variability is the basis of these nonquality labor conventions. The wage cannot be both a remuneration and a true resource for these individuals, and often assumes the character of a supplementary income. Although the skills of the worker are unimportant, the worker's specific character is important in the external labor market, where it is responsible for the mobilization of labor supplies. The convention depends on these nonwork, non-skilled-based identities. The frequent presence of a compromise between the workplace identity and the other identities of employees is the result. Paternalism, for example, could be interpreted as a compromise between the role of the family and the standardization of work.

The productivity convention does not need to be closely regulated since it is underpinned by an unemployment convention which tailors income from work and hence, labor costs, to fluctuations in demand. This convention transmits the charges of unemployment to the community members to which the workers employed belong. As in neoclassical theory, labor is a variable cost, both in terms of price and quantity.

The economic fluctuation of nonquality labor conventions creates uncertainty with respect to both the price and the volume of demand. Producers involved in these conventions fabricate standardized products dedicated to given, often very large, clients. The volume of work is adjusted in terms of hours of work. It adjusts itself immediately to demand variations and is externalized onto the surrounding community (ethnic or rural community or the family). Flexibility is thus connectd to precarity of employment. It is for these conventions that the compromise with the employment rules imposed by the state, which are rooted in industrial conventions, prove to be delicate, and often lead to violation or subterfuge, i.e. to use of legal loopholes and other forms of employment (temporary work, short-term contracts, subcontracting etc.)

\section{Conventions of industrial labor}

These last conventions, seen in the lower right section of Figures 14.2 and 14.3, combine rationalized work management and predictable markets. The industrial convention of productivity rests on a paradox which our familiarity with mass production and the large rationalized enterprise tends to mask. Work, having lost both its specialization and its dedication to an individualized demand, severs the link between labor and its product. The demand to which the firm addresses itself - especially the large firm-becomes independent of the market, which no longer evaluates the quality of the product, nor the 
quality of work. Quality is assured by incorporation of industrial standards into physical equipment and becomes more or less independent from the workers. Direct productivity incentives for workers disappear and have little to do with direct wages. By what means can they be reestablished? The response is complex and could have an unavoidably historical dimension (see the extract on "Polanyi"). In part, the response has to do with the emergence of social policies directed toward labor.

\section{K.Polanyi and the industrial labor conventions}

In industrial conventions, the individual has, in effect, lost all the traditional determinations upon which other conventions for the definition and insurance of the quality of work are based: "the trade," the family, the community, etc. Whence the problem raised by K. Polanyi (1944) when he analyses the crisis of economic liberalism and the "great transformation" needed to overcome this crisis: the deployment of economic and social policies by the state. How, given the progressive organization of the market for goods, does work, which-like money and land-depended upon "non-contractual organizations such as the family, neighbourhood, trade or religion," organize according to "the fiction" of the market?

As Polanyi stresses:

“...labour, land, and money are essential elements of industry; they must be organized in markets; in fact, these markets form an absolutely vital part of the economic system. But labour, land, and money are obviously not commodities.... Labour is only another name for a human activity which goes with life itself, which is in its turn not produced for sale but for entirely different reasons, nor can that activity be detached from the rest of life, be stored or mobilized.... None of them is produced for sale. The commodity description of labour, land and money is entirely fictitious.... Nevertheless, it is with the help of this fiction that the actual markets for labour, land and money are organized."

(Polanyi 1944:72)

This impossibility is nonetheless realized. Polanyi demonstrates that a purely social solution such as the localized paternalism of the Speenhamland system cannot only fail: the attempt to ensure that the wage does not descend below a certain minimum income, notwithstanding the market situation, leads to the lowering of the wage and to the collapse of the incentive to work: "Under Speenhamland society was rent by two opposing influences, the one emanating from paternalism...; the other organizing the elements of production... under a market system." (1944:80). Social institutions are linked, but in a complicated manner, to the quality of work and productivity. Far from being external, social institutions influence these latter two factors from the inside. In the case analysed by Polanyi, the maintenance of a locally restricted social identity was in contradiction with the universal identity of work emerging from the 
development of large-scale industry and from the extension of markets.

In industrial conventions, the worker becomes the bearer of social rights underwritten by the state and/or by agreements negotiated by cooperative elites. We shall deal with this point by limiting ourselves to the study of unemployment in France (Salais, Baverez, Reynaud 1986). In this case, access to social rights is subordinate to access to salaried work. Individuals must conform explicit norms of productivity for the production of goods. Conventions of industrial labor make the firm play an essential role in the definition of norms, and their observance according to procedures which are considered fair and legitimate by the participants. These procedures are structured around the concept of "employment," consisting of a skill and wage classification attached to the jobs (and not to the individuals), hiring and firing impersonal rules and a system of unemployment compensations. Thus, an overall convention of productivity establishing the link between the quality of work, quality of product, and remuneration is defined by means which are at once general (the state), decentralized (the firm), and intermediate (representative groups, agreements made between different levels of the state, branches, and firms). ${ }^{9}$ The products of these industrial conventions in the mass production industries facilitate the calculation of economic risk and offer the organizational capacity to manage collective risk, so that minimum revenue can be maintained even in the face of market fluctuations (job loss, the loss or insufficiency of individual productivity). This protection is effected via social policies embodied in labor law and negotiated by the groups referred to above. In the French industrial convention of unemployment, the responsibility vis-à-vis fluctuations of demand rests on the employers; but this responsibility has two faces in that, at the same moment, entrepreneur is committed to his personnel, but ultimately not committed because the state assumes ultimate financial responsibilities.

Thus, industrial labor conventions are congruent with macroeconomic fluctuations, for mass products markets are sensitive to the macroeconomic conjuncture through fluctuations in both consumption and investment. Adjustments in response to economic fluctuations are therefore carried out through short-term adjustments in the quantities produced and sold. Adjustment in response to a prolonged downturn which cannot be absorbed by building up stocks requires cuts in hours of work (short-term unemployment) or in the number of jobs (total unemployment). We must note the relationship between the mass product in theories of regulation (Boyer, 1986) and industrial conventions. But these conventions are considered by them only in an indirect way, as the support of an aggregate demand in macroeconomic policy. When they are analyzed, as we did, as the basis of risk-calculation by firms, the congruence of mass product with demana forecasting, the efficiency of wage inflexibility and the management of fluctuations as deviations from a trend may be seen. By the same token, it appears that these characteristics define markets from which other products (dedicated products), other markets (uncertain markets), and other forms of adjustment of wages and employment are excluded, and ignored.

There is, thus, a flexibility proper to industrial labor conventions, which rests upon the variability of the number of occupied jobs (or, via these jobs, of the hours of work). But it remains adequate only if the industrial definition of the quality of work is not threatened by the evolution of demand. In effect, if the standards of quality are thoroughly modified 
by the product markets, even the quality of the jobs offered will have to be changed; and what matters will, then, be not flexibility, but investment.

\section{CONCLUSION}

As always, the search for alternative answers to old theoretical questions raises an enormous number of issues. We shall conclude, tentatively, with two methodological observations. First, the empirical analysis of concrete labor relations can be considerably enriched by the approach used here. Though we have here only examined pure models, more complex situations could be analyzed in terms of compromises between conventions. For example, the recent increase in use of market conventions might not be the simple flexibilization of mass production, but a complex compromise between at least two systems of labor conventions-industrial and market. Second, the analysis of evolutionary dynamics and crises ${ }^{10}$ could be enriched by the analysis of distortions between conventions (lags, incoherences in the choices, and so on). For instance, a firm can move towards markets utilizing some conventions for the quality of products while not adapting its labor conventions for that of labor, given the autonomy of rules and institutions proper to each model of conventions. More generally, we can conceive of historical situations - such as that of much contemporary advanced capitalism - in which social institutions and the rules of employment policy can remain based upon industrial labor conventions while enterprises progress toward more market-based compromises, and examine the stability or unstability of such situations.

\section{ACKNOWLEDGMENTS}

I would like to thank Malcolm Mansfield for the translation and Michael Storper for his revision. This version has also benefited from a discussion with Suzanne de Brunhoff. 
